\title{
EL PROCESO CONSTRUCTIVO DE LA FACHADA PRINCIPAL DE LA UNIVERSIDAD DE SANTIAGO (1790-1805): su arquitectura y escultura.
}

\author{
Por \\ FERNANDO PÉREZ RODRÍGUEZ
}

Desde un principio el traslado de la Universidad al colegio de los recién expulsados jesuitas trae consigo muchos problemas que se incrementan, todavía más, cuando se decide construir un nuevo edificio para albergar las dependencias de una institución en auge. El considerable número de proyectos y planos existentes para su edificación junto a la participación de distintos arquitectos son una buena muestra de su problemática y compleja historia, como ha quedado patente en algunas investigaciones recientes ${ }^{1}$. Esta circunstancia es aplicable a la edificación de su fachada principal, cuyo proceso constructivo centra este trabajo con la pretensión de aportar nuevos datos que esclarezcan su particular desarrollo.

En la mayor parte de las publicaciones que tratan la historia de este edificio y en aquellas que se ocupan del arquitecto Melchor de Prado y Mariño se reitera que la primera fachada principal del nuevo edificio uni-

${ }^{1} \mathrm{M}^{\mathrm{a}}$ del C. FOLGAR DE LA CALLE, «El edificio de la Universidad» en Estudios El Patrimonio Histórico de la Universidad de Santiago de Compostela, Santiago, 1996, 44-55; y, sobre todo, F. PÉREZ RODRÍGUEZ, «Planimetría antigua» en Catálogo El Patrimonio Histórico de la Universidad de Santiago de Compostela, Santiago, 1996, 176-232.

"CUADERNOS DE ESTUDIOS GALLEGOS", Tomo XLV, Fascículo 110, Santiago 1998. 
versitario, antes de la posterior reforma decimonónica ${ }^{2}$, fue ejecutada siguiendo el proyecto confeccionado por este arquitecto ${ }^{3}$. Sin embargo, tal afirmación requiere ciertas matizaciones a la luz de algunos documentos que revelan interesantes claves no sólo para conocer en detalle el mencionado proyecto de Prado y Mariño, sino también para clarificar los avatares y transformaciones sufridas hasta su conclusión.

\section{LA ARQUITECTURA}

A principios de la década de los noventa del siglo XVIII tiene lugar el comienzo de las obras pertenecientes a la fachada occidental. Concretamente, en el año 1793 se acuerda su construcción siguiendo los planos realizados por el arquitecto Miguel Ferro Caaveyro. En un primer momento todo parece indicar que las obras van discurriendo por buen camino, sin embargo, hay datos posteriores que señalan una alteración en la disposición y ubicación de la escalera principal -el Dr. Vicente de Neira había modificado los planteamientos de Caaveyro-. La disconformidad manifestada por los miembros del claustro con semejante proceder conlleva su tratamiento en la reunión de 27 de abril de 1796. La lectura de los informes pedidos a los arquitectos José Pérez Machado y Juan López Freire es decisiva para el acuerdo adoptado: la formación de un plano o diseño que, plasmando la obra construida, el sitio donde se ubicó la escalera -ya empezada a construir por orden de Francisco de Neira- y la entrada del pórtico, se remita a la Real Academia de San Fernando para que manifieste su parecer. Es significativo que en dicho claustro el Rector mandase recoger por escrito la propuesta del Dr. Río $-<<$ es de sentir que la Escalera se construia en el sitio, y por el orden que demuestra el Plano del resto de la obra, y que todas las cantidades imbertidas, y gastadas en lo que es ageno, y estraño de dicho Plan deven de reintegrarse a la Uni-

\footnotetext{
${ }^{2}$ Véase al respecto J. A. SÁNCHEZ GARCÍA, «De la Reforma de Montero Ríos al Estatuto de Autonomía» en Estudios El Patrimonio Histórico de la Universidad de Santiago de Compostela, Santiago, 1996, 56-79.

${ }^{3}$ M. MURGUÍA, El arte en Santiago en el siglo XVIII, Madrid, 1884, 227; J. COUSELO BOUZAS, Galicia artística en el siglo XVIII y primer tercio del XIX, Compostela, 1932, 550.
}

"CUADERNOS DE ESTUDIOS GALLEGOS", Tomo XLV, Fascículo 110, Santiago 1998. 
versidad a costa del que, o los que causaron alteracion en la referida obra, digo en el referido Plano $>>-4$, claro ejemplo de la disparidad de opiniones que había sobre el asunto.

Una vez realizado el mencionado encargo por el arquitecto Fray Plácido Caamiña, se remite el plano a la Academia para ser sometido a consulta $^{5}$. El dictamen de la académica Comisión de Arquitectura apoya el primer proyecto del arquitecto Miguel Ferro Caaveyro porque contiene todas las ventajas $<<q u e$ desea el Claustro de la Universidad $>>^{6}$. Ante semejante respuesta, en la Junta de 9 de noviembre de 1797, se acuerda que Caaveyro formalice el plano de la portada, <<teniendo presente el sitio de la Escalera por el proyectado en el que debe ejecutarse, y asi mismo que en dicha Portada se han de colocar las Armas Reales, y proporcionar lugar para relox de campana procurando disponer del modo posible y mas conveniente las aguas del tejado de la Yglesia, mediante el nuevo edificio lleva maior elevacion: Ygualmente se acordó que dicho Arquitecto informe sobre el mejor modo de arreglar el trozo de obra que con la idea de formar en el la escalera se ha principiado ultimamente... >> .

Atendiendo a lo dispuesto, Miguel Ferro Caaveyro entrega cuatro diseños y su correspondiente explicación. El 16 de abril de 1798 son reconocidos por los claustrales y los diputados de la Junta de Obras, quienes deciden que el Rector y un arquitecto de su satisfacción los sometan a un

${ }^{4}$ Archivo Histórico Universitario de Santiago, Sección Histórica, Libro A-58, fol. 189.

${ }^{5}$ Para algunos planos y documentos mencionados cf. F. PÉREZ RODRÍGUEZ, op. cit., 176-232

${ }^{6}$ En el claustro de 6 de noviembre de 1797 se leyó la contestación de la Academia: $<<$ He presentado a esta Real Academia de Nobles Artes el plano del piso principal de la fabrica ya construida de esa Universidad ejecutado por Fr. Placido Camiño, que a consequencia del oficio que de su acuerdo diriji a V. S. en 10 de junio pasado me ha remitido con su carta de 6 de septiembre anterior. Y la Academia teniendo presente este ultimo plano, y los quatro antes remitidos con varios pareceres y despues de haberlos reconocido con la maior atencion para poder dar con el debido acierto su Dictamen en orden al sitio que sea mejor y mas oportuno para colocar en el la escalera principal de aquel edificio, acordó debia preferirse para la colocacion de dha escalera el Primer Proiecto del Profesor Dn. Miguel Ferro Caabeyro, a causa de hallarse en el todas las ventajas que desea el claustro de la Universidad.... Madrid 7 de octubre de 1797>>. Cf. A. H. U. S. Sección Histórica, Libro A-58, fol. 211v.

${ }^{7}$ Idem, fols. $213 \mathrm{r}$ y v.

"CUADERNOS DE ESTUDIOS GALLEGOS", Tomo XLV, Fascículo 110, Santiago 1998. 
detenido examen. Como resultado de esta labor se detectan varios reparos, se plantea su cotejo con los antiguos y, seguramente, se toma la determinación de no seguirlos. Así se explica la presencia del arquitecto académico Melchor de Prado y Mariño en la Junta de 9 de julio, a la que es convocado para mostrarle los planos, antiguos y recientes, e informarle de las ideas adoptadas por el Claustro -economizar el terreno, dotar de majestad y sencillez a la fachada y escalera- para que, de acuerdo a ello, forme una nueva traza.

\section{El proyecto de Melchor de Prado y Mariño}

Las escasas noticias conocidas sobre el proyecto ideado por Melchor de Prado para la fachada occidental de la Universidad compostelana, en su mayor parte reducidas a la simple afirmación de haberlo hecho sin más, han permitido opiniones dispares: Murguía la da como obra suya y Couselo Bouzas, más cauto, reseña solamente que este arquitecto $<<$ dió planos para el edificio de la Universidad, que, al parecer, no se siguieron>>. Este dilema requería ser investigado con el fin de aclararlo, pero ello sólo era posible recurriendo a las fuentes documentales.

Hasta ahora la desaparición de su aparato escrito y gráfico había condicionado nuestro conocimiento. Sin embargo, el hallazgo de un interesante memorial, presentado el 9 de agosto de 1798 por Melchor de Prado a la Junta de Obra de la Real Universidad, permite vislumbrar como era su proyecto, cuyo conocimiento continúa siendo incompleto al no conservarse su planimetría.

El encargo hecho un mes antes consistía en unos diseños que representaran $<<$ la idea de la parte de la Fachada, Zaguan, Escalera y mas piezas adiacentes del nuebo edificio de la Real Universidad>>, para lo cuál debía atenerse a los requisitos planteados por la Junta.

Después de inspeccionar y medir la parte ya construida, realizó un dibujo <<cuya forma y disposicion sencilla ha sido el resultado de diferentes tentatibas que seguramente fueran en menor numero si la estructura de la obra estubiera suxeta a mejores leyes $>>$. Se lamentaba de la irregular extensión de la fábrica y de otras circunstancias que limitaban su actuación, frustrando sus $<<$ mejores pensamientos $>>$. Con la finalidad de solventar estas sujeciones y compaginar majestuosidad, comodidad y economía, consultó <<las formas generales de la arquitectura con la situacion local de todo el edificio con relacion a la corta radiacion de 
los puntos de vista $>>$. Por esta última circunstancia estimó acertado que las columnas ubicadas en el medio de la fachada no avanzaran $<<$ mas que la porcion de terreno necesario al buen efecto de la decoracion $>>$. También juzgó que éstas debían tener una mayor altura.

La siguiente cuestión era el emplazamiento de la escalera, que considera debe ir en el lado derecho, <<como debe practicarse en todo buen edificio $>>$, ocupando el menor espacio posible para destinar el resto a las aulas. Su disposición en el lado del zaguán o pórtico era la más apropiada teniendo en cuenta la capacidad del terreno existente.

La definición gráfica de todo ello se reflejaba en cinco <<apariencias o vestigios $>>$, a saber, las plantas terrena y del piso principal, la fachada y dos cortes o secciones - una correspondiente al zaguán y la otra a la puerta de entrada a la iglesia-, $<<$ representando todo geometricamente $>>$.

La planta terrena llevaba el número 1 y en ella se especificaba la disposición del zaguán, escalera, y tres aulas proporcionadas. Una vez que se atravesaba la puerta principal, estando ya en el zaguán, al lado derecho había un primer arco por el que se accedía a la escalera de tres tiros. Esta desembocaba en un vestíbulo que servía de comunicación con la galería alta y habitación del Conserje. Si la intención era acceder a las oficinas del «terreno» se podía hacer a través de los otros dos arcos que conducían a la puerta central del patio y a la puerta frontera de la principal. La acertada disposición permitía aprovechar todo el área de la escalera y construir por debajo de ella otra que condujese al $<<$ subterráneo $\rangle>$.

Con el número 2 plasmaba la planta del $<<$ quarto principal $>>$, cuyas únicas diferencias respecto a la anterior eran la pieza dispuesta encima del zaguán y el menor grosor de las paredes. El resto de sus piezas guardaban correspondencia con las inferiores.

La fachada principal del edificio, representada en el número 3, poseía una decoración caracterizada por la sencillez y la grandiosidad. El ornato exterior se centraba en cuatro columnas de orden jónico - dos exentas y las otras adosadas a la pared-que, manteniendo una proporcionada distancia y alternándose con las ventanas, sostenían de manera majestuosa el entablamento. Este poseía un $<<$ tablero $>>$ cuya altura comprendía todo el friso y arquitrabe, y en él se disponía la inscripción que todo edificio público debía llevar según Real Providencia. Como coronación, encima del entablamento, iba colocado $<<$ un gracioso recivimiento en que esta apoyado con mucha magestad el escudo Real de España >>, sosteni- 
do en el aire por dos imágenes que representaban la Fama y el Genio, aludiendo a la protección dispensada por los Reyes.

El corte o sección, número 4, permitía observar las galerías baja y alta, la decoración del zaguán, el primer y segundo tiro de la escalera, y el vestíbulo que comunicaba con la galería alta y la primera pieza de la habitación del conserje.

El quinto diseño representaba la disposición de las aguas del tejado de la Iglesia y la puerta de comunicación con ella, que estaba en la galería baja.

Todos los dibujos contenían las dimensiones y relaciones exigidas para llevar a cabo su erección. Como precaución, recomendaba elegir un maestro que poseyera los fundados conocimientos en el arte de la construcción y los requisitos indispensables exigidos a $<<$ todo constructor para seguir la mente del Arquitecto $>$. Un atinado consejo que, además de evitar muchos problemas, permitiría concluir la obra con acierto ${ }^{8}$.

Prácticamente un año después, el 7 de julio de 1799, Prado y Mariño dirigía a la Junta un interesante informe señalando algunas consideraciones sobre los diseños, la ejecución de la obra y la intervención de arquitectos no titulados en semejantes empresas. A pesar de haberse aprobado los planos, recriminaba a la Junta no haber cumplido con su promesa de nombrarle Director de la fábrica, teniendo en cuenta que esta circunstancia había condicionado su labor ya que los planos no los había confeccionado de forma detallada, sino de manera general $<<$ para obtener la idea exterior del edificio, la del piso del terreno, y la del principal, sin atender a los otros despiezos que en obras de semejante entidad deben orientar el proyecto para hacerlo inteligible al artista mas consumado >>. Además, nos sigue diciendo, nunca habría pensado que la dirección pudiese recaer en un «sujeto» incapacitado para dirigir este tipo de obras ${ }^{9}<<$ pues la execucion de monteas, perfiles, partes en grande, y otros trabajos relatibos al decoro del edificio, a su ermosura, comodidad, firmeza, y economia >> eran propias de un arquitecto y no de un «oficial constructor», $<<$ sea quanta fuese su practica y exercicio en la materia $>>$. Aspectos que de-

\footnotetext{
${ }^{8}$ Véase apéndice documental, ${ }^{\circ} \mathrm{I}$.

${ }^{9}$ Se está refiriendo al maestro de obras, José Pérez Machado, que ha sido elegido como director de las obras.
}

"CUADERNOS DE ESTUDIOS GALLEGOS", Tomo XLV, Fascículo 110, Santiago 1998. 
bían ser considerados si se quería obtener un resultado feliz y no cometer errores irremediables ya que <<las obras buscan los buenos Artistas; pero los buenos Artistas no buscan las obras $>>^{10}$. También manifestaba que él no se había negado a la dirección de obra tan prestigiosa, sino que no había sido llamado. A continuación, volvía a arremeter contra la elección del director al señalar que la empresa no podía $<<$ salir bien corregida aun siendo dirigida por sujeto de iguales disposiciones que el que formo los diseños $>>\mathrm{y}$, menos, si éste no estaba $<<$ penetrado de aquellas relaciones ocultas, de aquellas formas sencillas y grandiosas que ligan entre si y con el todo unas partes con otras, aciendo agradable lo necesario, y lo necesario agradable $>$. En fin, Prado y Mariño era partidario de que al frente de los edificios públicos estuvieran aquellos sujetos de conocida idoneidad y que hubieran aprobado el pertinente examen de las Academias ${ }^{11}$.

Antes de esta reprimenda, el 11 de agosto de 1798, tras analizar el informe y planos realizados por Prado, se aprueban $<<$ en todas sus partes $>>$. Doce días más tarde se le abonan dos mil reales de vellón por su trabajo y se suspende la continuación del edificio hasta que se decida la forma de contrato.

Se retoma el 21 de mayo de 1799 adoptándose las siguientes resoluciones: ejecutar la obra por asiento, buscar un buen celador para que diariamente asista y vigile las obras, formalizar el contrato y entregar la piedra de sillería del edificio antiguo al mejor postor. La excesiva postura presentada por el maestro Ramón Fontela y la posterior incomparecencia de otros postores conlleva que la Junta, en su reunión de 5 de julio, elija a José Pérez Machado por ser <<el menos malo, y en cierto modo el mas a proposito por su pericia, y practico conocimiento que tiene del edificio, y otras circunstancias $>>$. Pasados dos días, el elegido acude a la Junta y, después de ver el plan aprobado que debe seguir sin alteración o variación alguna, manifestó que $<<$ no tenia dificultad en su ejecucion, por haberlo inspeccionado mui antes de aora, y que en el caso se le ofreciese en el discurso de la obra alguna duda la propondría a la Junta para que

\footnotetext{
${ }^{10}$ Con semejante afirmación Prado y Mariño se contradice, pues con su actuación predica todo lo contrario ya que no espera a que le encarguen las obras, sino que es él quien las busca a toda costa.

11 Véase apéndice documental, $\mathrm{n}^{\circ} \mathrm{I}$.
}

"CUADERNOS DE ESTUDIOS GALLEGOS", Tomo XLV, Fascículo 110, Santiago 1998. 
le señalase el arquitecto con quien devia resolverla, o lo haría el arquitecto Prado actor de dicho plan si fuere necesario, y se hallase en el lugar $>>$. También acata las obligaciones señaladas por la Junta de asistir personalmente ocho horas diarias, elaborar las monteas, perfiles y $<<l o$ mas relativo al decoro del Edificio a su hermosura, comodidad, firmeza y economia $>>$. Por todo ello recibiría veinticuatro reales diarios ${ }^{12}$.

En la siguiente reunión, se nombran a los miembros que van a desempeñar los restantes cargos relacionados con la construcción: Juan Gómez será el segundo maestro o aparejador, con el suelo de nueve reales diarios; Alberto Camino ocupará el de aparejador de monte, con ocho reales de jornal, y Silvestre Blanco actuará como sobrestante y alistador bajo la misma cantidad. La incompatibilidad de dos cargos en una misma persona determina el nombramiento de Pedro Buceta para desempeñar la plaza de alistador.

El 22 de agosto la Junta trata el modo y forma de ejecutar la obra en el sitio fijado por el plano aprobado, que requería demoler alguna parte. Este hecho es analizado a la luz de la traza y de varios informes acordándose, unánimemente, <<que no se demuela parte alguna de la obra echa, y solo para colocar las columnas abanzadas que adornan el portico en los sitios, y lugares que demuestra el Plano, se roze en la pared ya echa la cabidad que sea necesaria para introducir, ligar, y atizonar segun arte las piedras, con lo qual se consigue la total seguridad del Edificio y el aorro de cantidad considerable que se gastaria en la demolicion $>>{ }^{13}$. El acuerdo es comunicado al maestro director Pérez Machado para que lo tenga en cuenta en su trabajo.

\section{Modificaciones realizadas al proyecto}

Las primeras modificaciones del proyecto de Melchor de Prado surgen a raíz de la fabricación de algunas partes concretas como es el caso de la escalera principal que vuelve a ser asunto de juicio. En la reunión del 5 de septiembre, el Rector advierte que la escalera, desde la entrada principal al piso noble, no sólo no se corresponde con la «majestad» del edificio, sino que también tiene insuficientes luces porque $<<l a$ ventana $o$

\footnotetext{
${ }^{12}$ A. H. U. S. Sección Histórica, Libro A-58, fols. 254r y v.

${ }^{13}$ Idem, fol. $261 \mathrm{v}$.
}

"CUADERNOS DE ESTUDIOS GALLEGOS", Tomo XLV, Fascículo 110, Santiago 1998. 
Reja por donde las recibe no cabe en el medio de la mesa primera, segun debiera para iluminarla toda, y ademas de ello en su desemboque o final en dicho piso noble, no recive mas claridad que la que se le comunica por la parte interior del claustro $>>$, defecto que no puede permitirse $<<$ en un Edificio de esta naturaleza, cuia fachada en todas sus partes debe ser proporcionada y arreglada al Arte, sin que por ello se perjudique a la economia de la construccion interior $>>$. Se solicita entonces el parecer del maestro director, Pérez Machado, tras lo cuál determinan $<<q u e ~ l a$ escalera principal que esta a la entrada de la puerta de este Edificio sea, y deva ejecutarse en dos ramales distintos, el uno a la derecha de dicha puerta, segun manifiesta el Plano, y el otro a la Yzquierda, en el sitio en que dicho Plano señala una mui estrecha Aula, a la que no puede darsele la cavidad y ensanche que representa el referido Plano por ser mui costoso demoler la pared que está ya construida, y deveria segun alli se señala bolber a edificarse de nuebo a mui corta distancia, en cuios embages ademas de atrasarse la obra se gastarian quantiosas sumas $>>^{14}$.

Nuevamente el Rector, en la junta de 24 de abril de 1800, se hace eco de las insinuaciones del director de obra, a saber, que la ejecución de la bóveda del pórtico, según el plano de perfil que rige, no puede ejecutarse por diversos motivos: la falta de correspondencia entre los arcos de medio punto, que dan paso a la escalera y crujía del claustro, y la bóveda rebajada; el quebranto de la imposta que sostiene la bóveda y el rebaje de la puerta principal en un pie que altera el orden correcto de su arco, cuyo dintel debía guardar el nivel de las ventanas primeras de la fachada. Ante la «gravedad» del asunto, la Junta hace concurrir a Pérez Machado, quién, además de corroborar lo dicho, presenta un diseño propio representando la bóveda y arcos $<<$ de una misma figura $>>$. El consiguiente examen resulta ser favorable y recibe la aprobación para que en su conformidad se proceda en la obra. Al mismo tiempo, se adopta otra serie de acuerdos como el que la bóveda deba ejecutarse de cielo raso porque $<<$ en este caso no tiene el espesor que corresponde, y en aquel sitio no esta recargada con peso alguno $>>$, que la confección del pasamanos de la escalera principal sea de hierro y no de cantería por su mayor firmeza y menor

\footnotetext{
${ }^{14}$ Idem, fol. 264v.
} 
coste, y que los dos arcos correspondientes a la anterior secretaría sean demolidos ${ }^{15}$.

Y si la parte interior sufre modificaciones, otro tanto le ocurre al exterior del edificio. En la Junta de 20 de febrero de 1802 se trata sobre la conclusión de la fachada y, relacionado con ello, sobre algunos de los reparos expuestos por el arquitecto director: si debe rematarse con frontón $<<$ o a la manera que esta representado en el plano lebantado por el Arquitecto Dn. Melchor de Prado >>, y si debe suprimir el paño de inscripción manifestado en el mismo plano sobre las dos columnas intermedias. Después de debatirlo se decide no introducir variación alguna, $<<$ prebiniendo al Arquitecto director se arreglase a lo que representa el citado Plano aprobado por el claustro $>>{ }^{16}$.

Sin embargo, el 5 de mayo, el presidente Agustín de Vales manifiesta su disconformidad con el remate que se le quiere dar a la fachada por parecerle $<<$ desproporcionado, e irregular, ya por lo mui costoso, e ya tambien por los muchos incombenientes y perjuicios que pueden seguirse a la misma obra>>, y propone la realización del frontón <<que está demostrado en la pared del lienzo de la Biblioteca $>>$ por ser más útil, económico y «arreglado al arte» ${ }^{17}$. No se dispuso nada al respecto por considerar que la Junta no tenía facultades para variar el plano aprobado por el Claustro, pero éste, en su reunión de 10 de mayo, acordará conformarse al dictamen que la Junta determinase en el asunto. Definitivamente se adopta la modalidad del frontón como remate de la fachada, concluyéndose a finales del mes de agosto ${ }^{18}$.

Como se puede comprobar, el proyecto diseñado por el arquitecto académico sufre considerables modificaciones no sólo en el interior sino también en el exterior. Todo parece indicar que sólo se respetó la disposición de las cuatros columnas de orden jónico gigante, pues la esencia de esta fachada con frontón, incluyendo la escalera principal de su interior, ya estaba plasmada en los distintos proyectos presentados por el arquitecto Miguel Ferro Caaveyro.

\footnotetext{
${ }^{15}$ Idem, fol. $268 \mathrm{v}$.

${ }^{16}$ Idem, fol. $274 \mathrm{v}$.

${ }^{17}$ Idem, fol. 275.

${ }^{18}$ El desarrollo de las obras relativas a la entrada y acceso a la fachada principal pueden consultarse en F. PÉREZ RODRÍGUEZ, op. cit., 222-231.
}

"CUADERNOS DE ESTUDIOS GALLEGOS", Tomo XLV, Fascículo 110, Santiago 1998. 


\section{LA ESCULTURA}

Una vez concluida la estructura arquitectónica de la portada era necesario acometer los trabajos relativos a su decoración, es decir, la confección de las estatuas de Minerva, los niños y el escudo de Armas Reales ${ }^{19}$. La Junta de Obra faculta a dos de sus miembros, Agustín Vales Vaamonde y José Vicente de Neyra, para que se encarguen de todos los trámites referentes al diseño, contratación y ejecución de las obras escultóricas. El hecho de hacer pública la realización de semejante obra permitió que muchos maestros escultores se interesasen y remitiesen sus informes o propuestas. Así, el 21 de julio de 1802, el profesor de escultura Manuel de Prado y Mariño se dirige al Rector y Junta de Obra de la Universidad suplicando se le encomiende la obra de escultura que se piensa realizar para coronar la fachada occidental. Nuevamente, el 11 de septiembre, envía un informe exponiendo que, cumpliendo con el encargo que le ha hecho el Sr. Vales, calcula el coste de la escultura pensada para el remate en 27.470 reales, con la condición de que el escultor sólo aporte por su cuenta los oficiales necesarios para este trabajo, quedando a cargo de la Universidad el resto de los gastos derivados de arrancar, desbastar y conducir la cantería, <<armar las figuras en bruto en el taller $>>$, poner las alas de cobre, algún trofeo, grapas, espigos, herramientas y estadas, subir y asentar las figuras en su lugar bajo la inspección del escultor. Éste debería presentar un modelo no inferior a media vara de cada figura para acreditar su valía, aspecto que también se podría comprobar por las obras que ha realizado, y dar las correspondientes fianzas. El informe se convierte en una propuesta personal pues, al final, suplica que si lo consideran sujeto competente se la encarguen a él porque su pretensión no es económica, sino adquirir fama y reconocimiento ${ }^{20}$. También se consulta el parecer del escultor José Ferreiro, quién entrega su informe el día $14^{21}$. Otros escultores que muestran interés por la obra son Antonio Pernas y Bartolomé

${ }^{19}$ M. MURGUÍA, op. cit., 211; A. A. ROSENDE VALDES, «La escultura de la Universidad de Santiago hasta la Guerra Civil», en Estudios El Patrimonio Histórico de la Universidad de Santiago de Compostela, Universidad de Santiago de Compostela, 1996, 112-113.

${ }^{20}$ Véase apéndice documental $n^{\circ}$ II.

${ }^{21}$ Ibidem.

"CUADERNOS DE ESTUDIOS GALLEGOS", Tomo XLV, Fascículo 110, Santiago 1998. 
Fernández. El primero presenta su postura al día siguiente, en la cantidad de 24.000 reales de vellón, manifestando considerarse muy capacitado para este arte, lo que trata de demostrar mencionando algunas de sus obras -las fuentes de Neptuno y de la Fama en la ciudad de A Coruña y el panteón de Malvar en su capilla de Salcedo- y poniendo en «duda» la capacidad de los otros candidatos; sobre Manuel de Prado argumenta que no ha realizado ninguna obra pública de cantería que acredite su capaci$\mathrm{dad}^{22}$. El segundo maestro estatuario lo hace el 17 de septiembre en 25.000 reales $^{23}$.

De los distintos informes recibidos se escoge el de José Ferreiro, al que le comunican cuales son las estatuas elegidas por el claustro para coronar el frontis de la fachada. De acuerdo con ello, este escultor forma un diseño que recibe la aprobación de la Junta. El 31 de enero de 1803 se escritura el contrato conforme al diseño referido, a una serie de condiciones y por la cantidad de 30.000 reales de vellón ${ }^{24}$. A pesar de no haberse localizado el dibujo de Ferreiro, todo parece indicar que éste se correspondía plenamente con la obra materializada, ya que no hay ninguna disposición contraria. Los pensamientos del claustro en cuanto a la decoración escultórica propuesta se puede intuir de las noticias aportadas por los documentos presentados por los escultores. En ellos se habla de dos grupos, uno compuesto por las estatuas o figuras y el otro por el escudo de las Armas Reales. En cuanto al primero sólo se especifican las representaciones de niños con alas. Llama la atención que en ningún momento se haga alusión a la estatua de Minerva, aunque se debía dar por supuesto que apareciera ésta u otra deidad semejante, sobre todo teniendo en cuenta que tal sugerencia ya la había hecho el arquitecto Miguel Ferro Caaveyro en su proyecto de 1797, en el que también incluía a los niños bajo el nombre de genios. Esto viene a confirmar que los planos presentados por Caaveyro para la fachada no fueron del todo olvidados.

Para que la obra quedara concluida definitivamente era necesario proceder a blanquear estas obras escultóricas. El 23 de julio de 1804 se consultan las propuestas hechas por los pintores Plácido Fernández Arosa y

\footnotetext{
${ }^{22}$ Ibidem.

${ }^{23}$ Ibidem.

${ }^{24}$ Couselo Bouzas recoge algunas noticias sobre esta obra en su libro, p. 324. El contrato está recogido en el apéndice documental $n^{\circ}$ III.
}

"CUADERNOS DE ESTUdIOS GALLEGOS", Tomo XLV, Fascículo 110, Santiago 1998. 
Manuel García para blanquear las estatuas, escudo real, leones y $<<t a-$ blero $>>$ del frontispicio de la fachada universitaria ${ }^{25}$. Al día siguiente Vicente José de Neira procede a rematar la pintura con el maestro pintor Plácido Fernández ${ }^{26}$. A través de ellas podemos descubrir cuales son los pasos a seguir cuando se pinta una escultura granítica destinada al exterior. En primer lugar se limpia el polvo de las piezas y se elimina la cal de las juntas para embetunar estas últimas de óleo. A continuación se cierran los poros existentes en la piedra dando una mano de aceite de linaza caliente mezclado con $<<$ litargirio $u$ otro desecante parecido $>>$, ya que esto facilita la fijación del color. Después se le aplican cuatro manos $<<a$ brocha de albaraide bien pastoso molido con aceite de linaza $>>$. Luego se dan otras manos con una masa obtenida de la mezcla de albaraide fino y aceite craso de nueces, <<cuias manos habran de ser a pulimento de modo que se consiga tersura e igualdad en la superficie, como igualmente blancura en todas las partes que componen la decoracion del frontispicio, es a saber estatua de Minerva, grupos, escudo real, leones, y tablero donde se ha de colocar la inscripcion $>>$. Y finalmente, se doran los trofeos de las estatuas y las letras de la inscripción que debían grabarse en la piedra, $<<$ con panales mas incorporados que los ordinarios $>>$. Todos estos pasos deben ser inspeccionados y avalados por el encargado que la Junta nombre. Una vez concluido el trabajo se somete a un reconocimiento para comprobar que ha sido realizado de acuerdo a lo prescrito. El pago de la cantidad ajustada de 12.000 reales de vellón se efectuará una vez conseguido el visto bueno a la obra.

El 9 de octubre Plácido Fernández Arosa dirigía un memorial a la Junta resumiendo los sucesos acaecidos. Con él se había ajustado la pintura de las estatuas y esculturas de la fachada principal. Cuando la concluyó se lo comunicó al decano presidente de la Junta, Agustín de Vales, quién pasó a reconocerla, acompañado del pintor Mariño, resultando tener diferente color el escudo y las estatuas. Esta diferencia se debía al fuerte aire que hizo cuando le dio la última mano a éstas últimas y al polvo desprendido al demolerse la estada. La solución consistía en darle

${ }^{25}$ A. H. U. S. Sección Histórica, libro de las Juntas de la obra desde el año de 1797 hasta el 1805 .

${ }^{26}$ J. COUSELO BOUZAS, op. cit., 299.

"CUADERNOS DE ESTUDIOS GALLEGOS", Tomo XLV, Fascículo 110, Santiago 1998. 
dos manos más de albaialde, comunicación hecha por el Sr. Vales y aceptada por el asentista. Sin saber por qué razón el decano le anunció que no trabajase en las estatuas hasta nueva orden. Ante esta nueva decisión Fernández Arosa pide una aclaración. Comenta que este tipo de pintura, por su composición, requiere tiempo para que quede blanca, condición no necesaria si fuese $<<$ de cal de Lugo y agua de cola $>>$. Considera el resentimiento del perito como única razón plausible de la reprimenda recibida. Además, esta empresa la había costeado de su bolsillo sin que la Universidad le hubiera pagado nada y, por ello, suplicaba se hiciese cuanto antes la estada para que pudiera dar las dos manos correspondientes a las estatuas y, así, poder cobrar el importe ajustado en la escritura del contrato ${ }^{27}$.

El 25 de octubre de 1804 Manuel de Porto y Mondragón, profesor de pintura y dorado, presentaba el reconocimiento que, a petición de Agustín de Vales, había hecho de la pintura ejecutada por Plácido Fernández. En él exponía los fallos cometidos por el asentista: la ejecución de las capas de pintura blanca era desastrosa ya que en algunas partes se había cargado en exceso y en otras se percibía la aspereza de la piedra. Estas pruebas demostraban que el ejecutor $<<$ no tenia practica ni instrucion, ni era facultativo $>>$. A pesar de todo la pintura estaba segura. También reconoció el material de albaialde fino y molido preparado en cazuelas que debía emplearse para dar dos manos más; una pastosa sobre todo en aquellas zonas que están mal cubiertas, y otra general $<<$ con buen varniz y a pulimento $>>$. Si no llegasen daría otra con el fin de conseguir cubrirlas correctamente para que el color quede terso y las estatuas parezcan realizadas en mármol. Respecto al escudo de armas no presentaba ninguna corrección por estar bien ejecutado ${ }^{28}$.

Otro memorial presentado por Plácido Fernández el 26 de noviembre aclara algunos puntos hasta ahora oscuros. Cuando terminó el blanqueo de las esculturas lo notificó a los miembros de la Junta para su reconocimiento, lo que se ejecutó mandándose deshacer las estadas. En la operación se levantó polvo y las partículas se pegaron a las estatuas. Cuando el presidente acudió a la Ciudad hizo un reconocimiento con un perito expre-

\footnotetext{
${ }^{27}$ Veáse apéndice documental $\mathrm{n}^{\circ}$ III.

${ }^{28}$ Ibidem.
}

"CUADERNOS DE ESTUDIOS GALLEGOS", Tomo XLV, Fascículo 110, Santiago 1998. 
sando que el escudo estaba bien y que las estatuas necesitaban alguna mano de blanco, encargo que había realizado sin dilación alguna. Nuevamente se hizo otro reconocimiento encontrando algunas imperfecciones que fueron corregidas y sometidas a otro reconocimiento que resultó ser favorable en todas sus partes. La resistencia del decano presidente Vales a pagar al contratista la cantidad estipulada no era comprendida por éste último, quién reclamaba lo que le pertenecía ${ }^{29}$.

Posiblemente, los dos últimos reconocimientos expresados en el memorial de Fernández Arosa se correspondan con los ejecutados por Antonio Mariño, pues aunque su fecha es posterior, los datos referidos tienen una exacta correspondencia. El primero lo realiza el 23 de abril de 1805 expresando $<<q u e$ antes de aora habia pasado a reconocerlas de orden del Dr. Dn. Agustin Vales y hallara ser indispensable darle dos manos de albayalde fino a pulimento, las que en la actualidad reconocia se hallaban dadas por orden del dho Fernandez, y segun las experiencias que hizo contempla estar dadas con seguridad y firmeza, y executado todo segun contrata a que se halla informado, y solo juzga preciso cubrir algunas manchas ocasionadas del agua que despidio el tinte de las maderas de las estadas y retocar algunas faltas que se advierten en los trofeos, y especialmente toda la lanza, sin que hubiese advertido otra falta $>>$. El segundo lo realiza un mes después comprobando que los «errores» mencionados anteriormente <<estan reparados a perfeccion y con toda susistencia $>>^{30}$.

En lo referente a la resistencia de Vales, posiblemente, se deba a que la inscripción no había sido dorada, pues el 12 de junio de 1805 el pintor Fernández Arosa se obliga a su dorado y, así, concluir su trabajo para poder cobrar la cantidad estipulada ${ }^{31}$.

Distintos materiales gráficos permiten conocer las distintas fases que han alterado esta fachada. Su estado original está reflejado en una litografía realizada por Núñez Castaño en la tercera década del siglo XIX (Fig. 1) ${ }^{32}$.

\footnotetext{
${ }^{29}$ Ibidem.

${ }^{30}$ A. H. U. S. Sección Histórica, leg. 164 , mazo $2^{\circ}, n^{\circ} 24$, s. f.

${ }^{31}$ Veáse apendice documental $\mathrm{n}^{\circ}$ III.

${ }^{32}$ Archivo Municipal de A Coruña, Colección Martínez Barbeito. En el Museo de Pontevedra debe existir otra litografía igual según refiere $M$. del C. FOLGAR DE LA CALLE, op. cit., 53.
}

"CUADERNOS DE ESTUDIOS GALLEGOS", Tomo XLV, Fascículo 110, Santiago 1998. 
La siguiente fase, correspondiente a la modificación de las escaleras de acceso realizada en 1845 bajo el proyecto del arquitecto Manuel de Prado y Vallo ${ }^{33}$, queda plasmada en una fotografía (Fig. 2) ${ }^{34}$. Otra reforma posterior, efectuada a finales del siglo pasado, alteró considerablemente la fachada con el añadido de un nuevo piso y la supresión del frontón y las estatuas que servían de coronamiento (Fig. 3). El grupo escultórico de Minerva y los genios, después de «alojarse» durante algún tiempo en el patio del colegio de San Clemente (Fig. 4) ${ }^{35}$, se trasladó al mirador de la Facultad de Químicas donde actualmente puede contemplarse, un poco alterado por la pérdida de algunos atributos que portaban la diosa Minerva y los genios ${ }^{36}$. (Fig. 5).

${ }^{33}$ Véase F. PÉREZ RODRÍGUEZ, op. cit., 228-231.

${ }^{34}$ A. M. C. Colección Martínez Barbeito; A. VIGO TRASANCOS, «El arquitecto benedictino Fray Plácido Caamiña y su proyecto de Casas Consistoriales y Cárceles para la ciudad de Ferrol (1791) en Cuadernos de Estudios Gallegos, 1995, 296-297.

${ }^{35}$ Fuente: J. L. CABO VILLAVERDE y P. COSTA BUJÁN, Patio do Colexio de S. Clemente (P. Mas, 1919) en Compostela. Memoria fotográfica.

${ }^{36}$ A. A. ROSENDE VALDÉS, op. cit., 112-113.

"CUADERNOS DE ESTUDIOS GALLEGOS", Tomo XLV, Fascículo 110, Santiago 1998. 


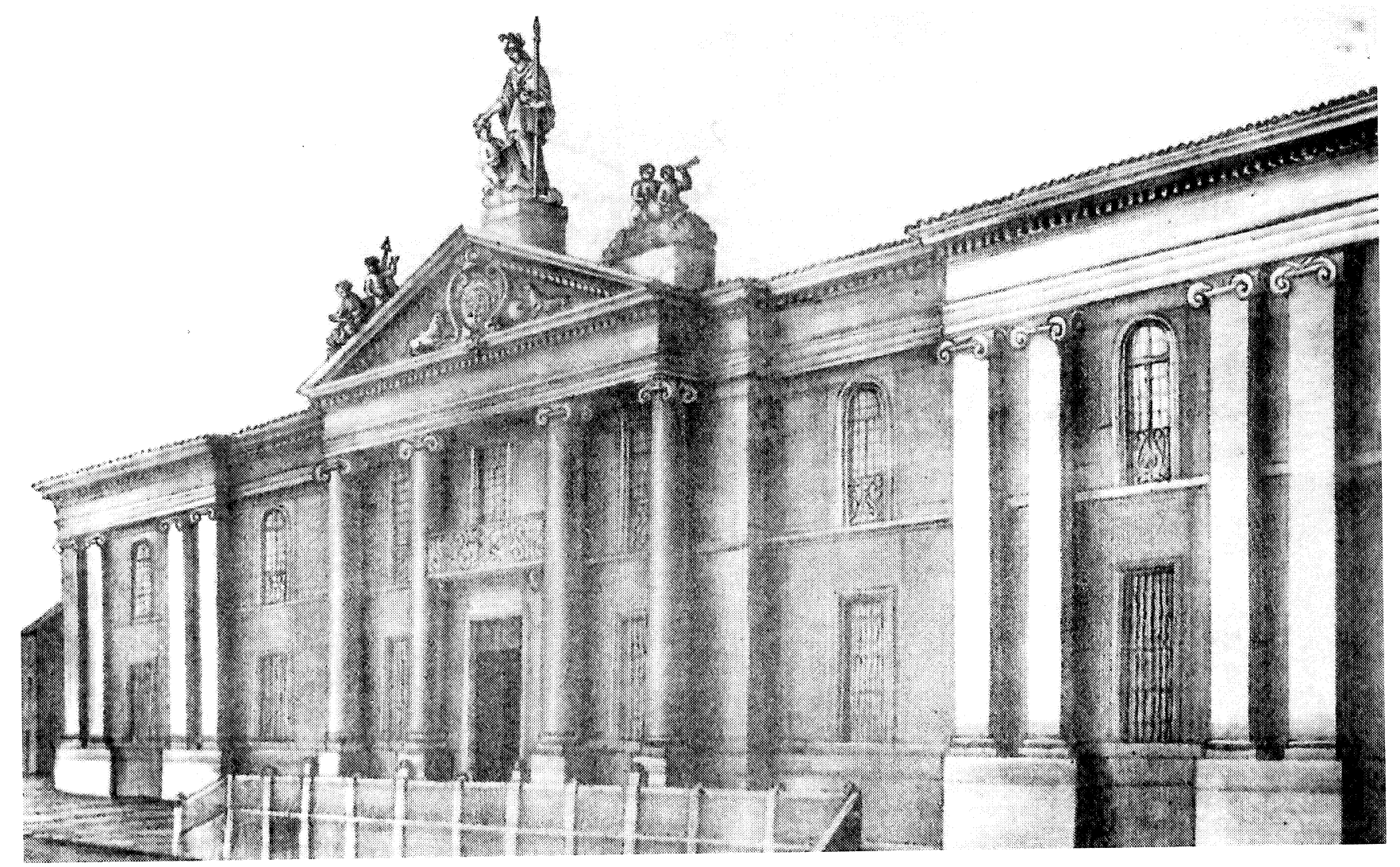

Fig. 1.- La Universidad de Santiago. 


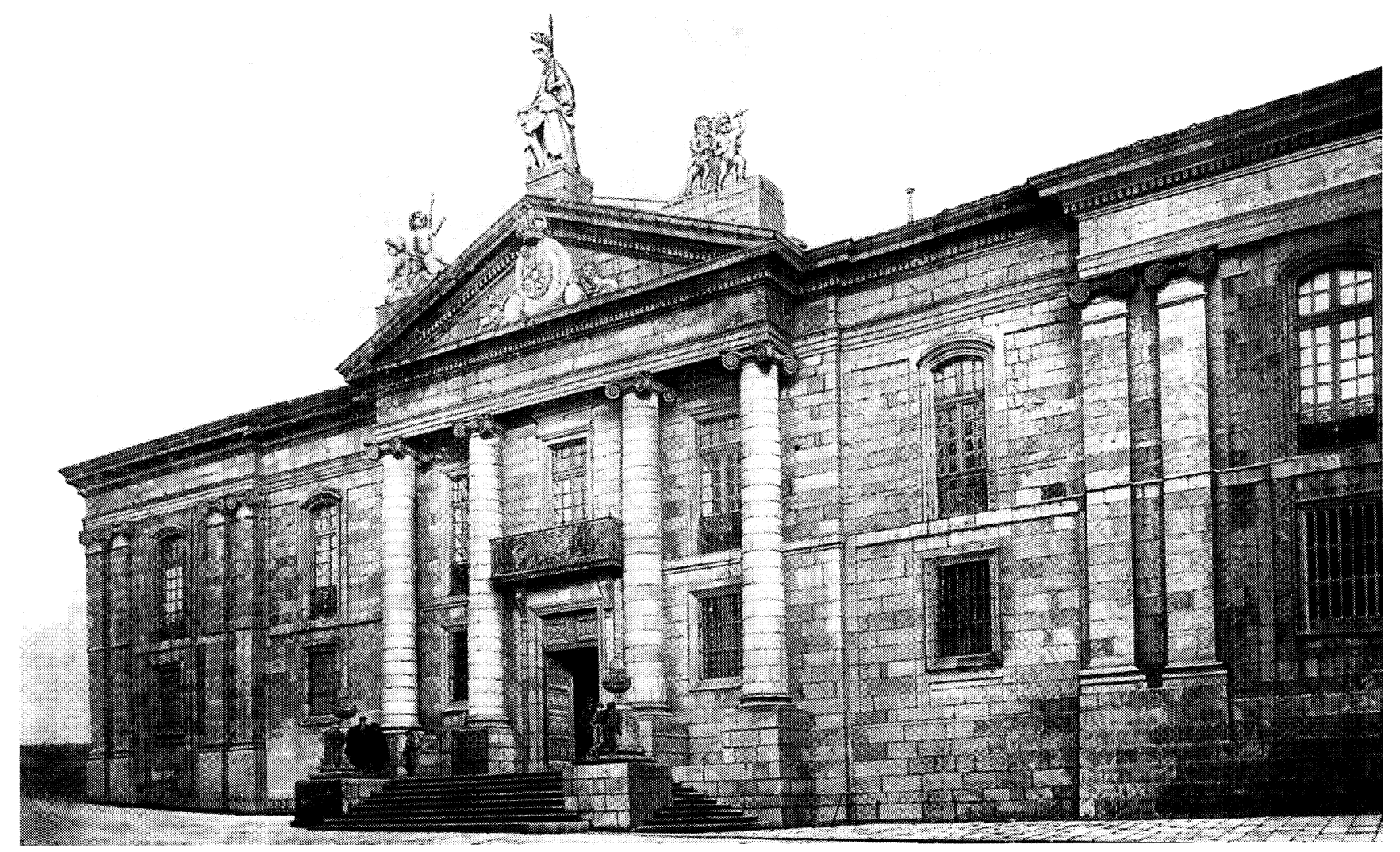

Fig. 2.- Fachada Principal de la Universidad de Santiago de Compostela. 


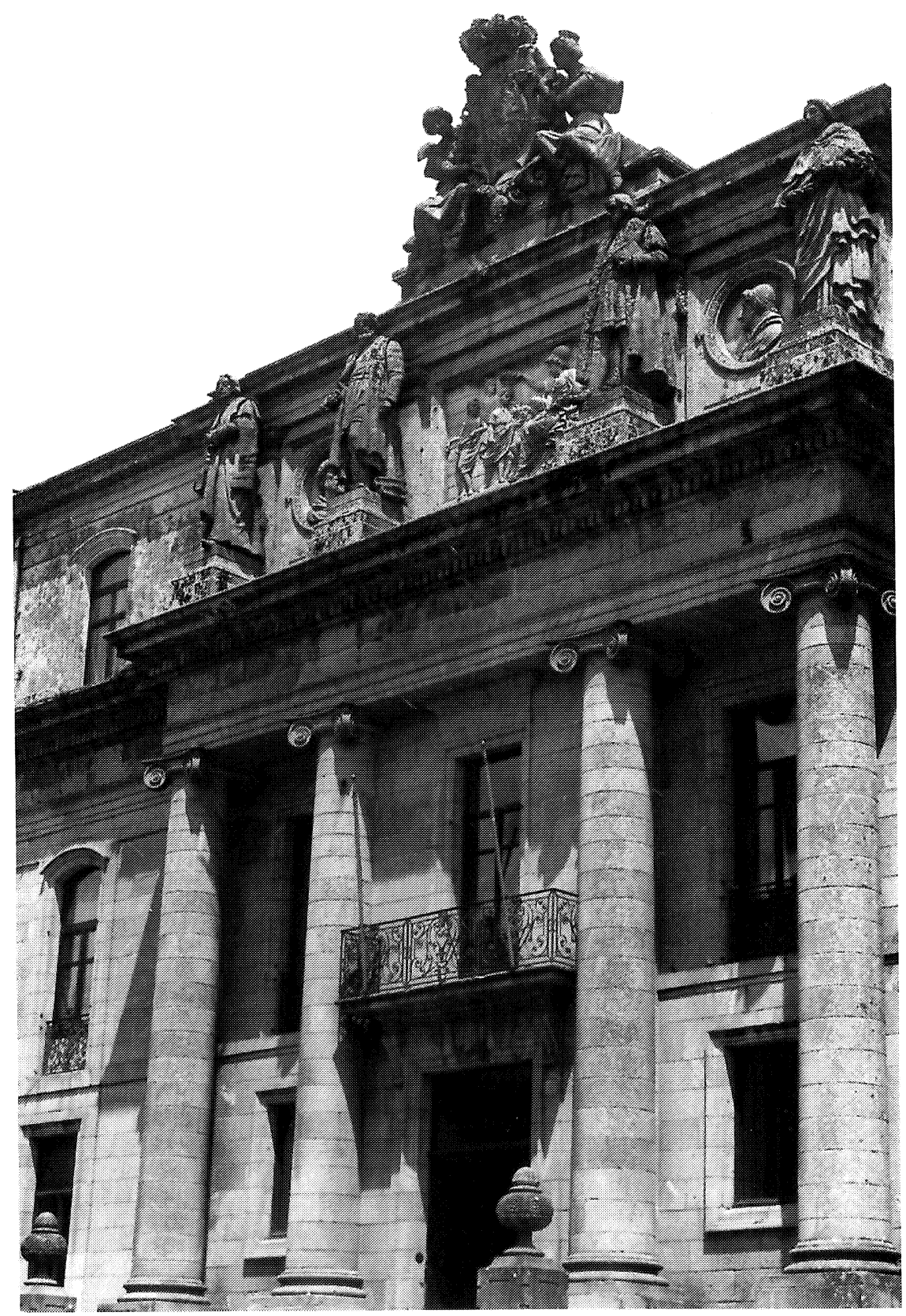

Fig. 3.- Actual fachada de las Facultades de Geografía, Historia y Arte. 


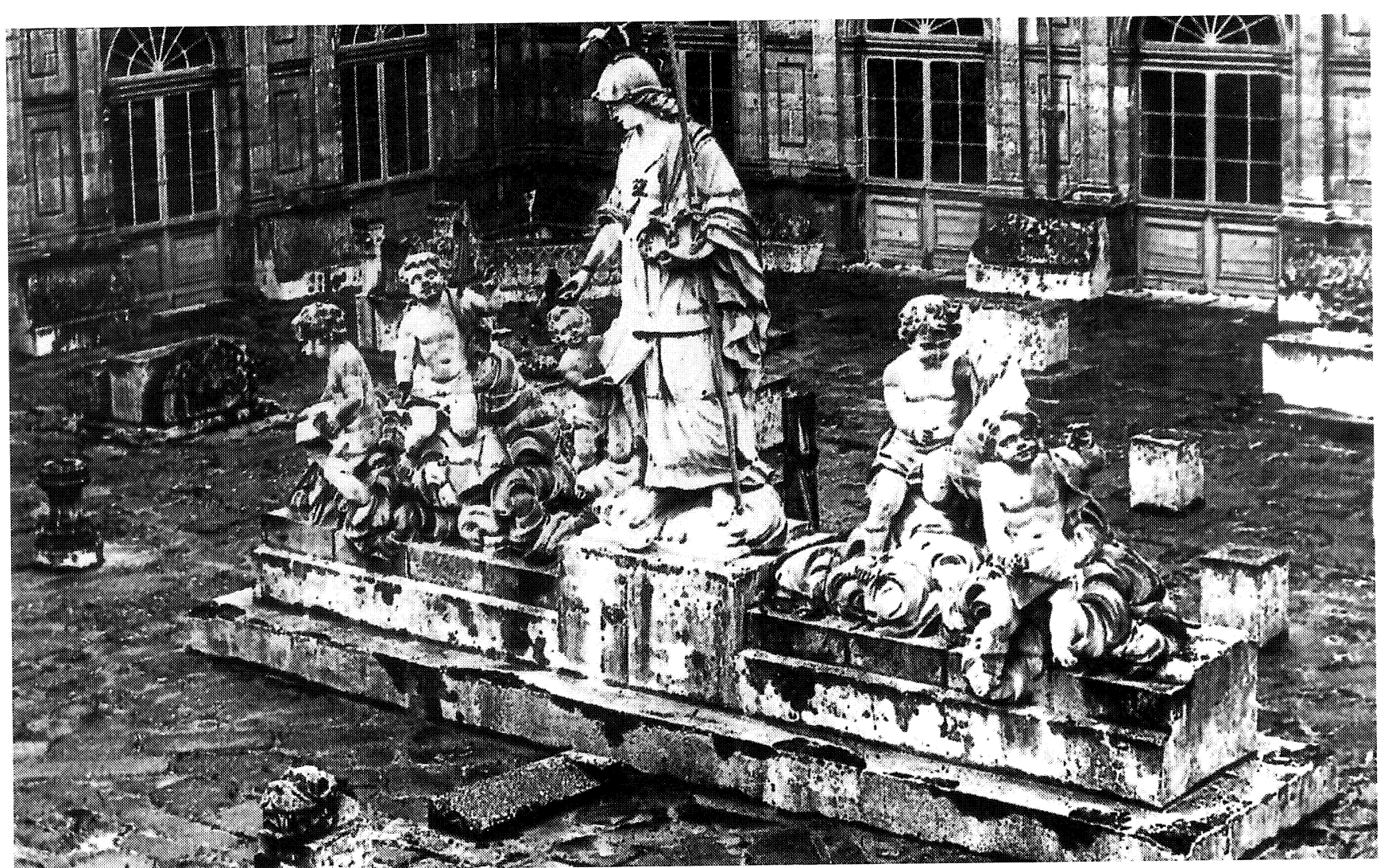

Fig. 4.- Grupo escultórico ubicado en el patio del Colegio de San Clemente. 


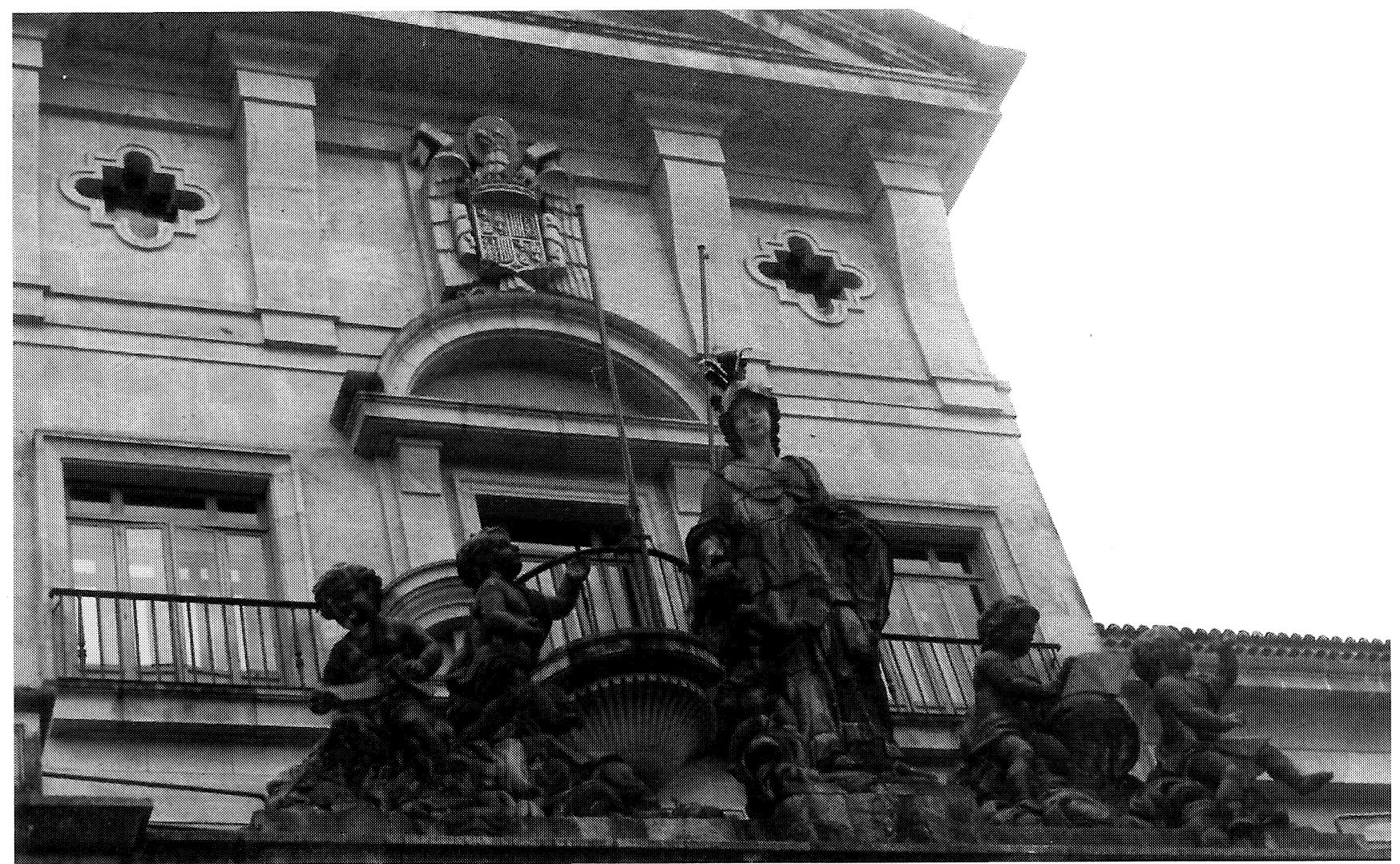

Fig. 5.- Mirador de la Facultad de Químicas. 


\section{APÉNDICE DOCUMENTAL}

$\mathbf{N}^{0}$ I. Documentos sobre la obra arquitectónica

Memorial de Melchor de Prado y Mariño, 9 de agosto de 1798.

$<<$ Señores Retor y Señores de la Junta de Obra de la Real Universidad.

En cumplimiento del encargo que V. S. se ha servido hacerme de los Diseños que debian representar la idea de la parte de Fachada, Zaguan, Escalera, y mas piezas adiacentes, del nuebo edificio de la Real Universidad, teniendo presente las calidades propuestas por V. S. y mas requisitos concernientes al asunto: digo que despues de haber calculado todas las dimensiones y relaciones que ofrece la parte de la fabrica ya construida, y combinandolas asi en planta como en elevacion, me resolvi señalar el partido que manifiesta el Diseño que acompaña, cuya forma y disposicion sencilla ha sido el resultado de diferentes tentatibas que seguramente fueran en menor numero si la estructura de la obra estubiera suxeta a mejores leyes.

Desayudó notablemente la arte la desgracia de no tener la fabrica la regular estension, y mas circunstancias indispensables, relatibas al uso y destino de este edificio; cuyas suxeciones me fustraron siempre los mejores pensamientos, y por lo mismo al presente se puede apreciar por el menos malo de quantos se han podido y podían tantear; pues aunque no presenta aquella magnificencia que era debida a un edificio de esta especie, con todo me persuado que satisfará el designio de V. S. y aun de los mas inteligentes atendidas las restriciones que se observan.

Para salbar las predhas suxeciones y conciliar lo magestuoso con la comodidad, sin perder de vista la economia, tube que consultar las formas generales de la arquitectura con la situacion local de todo el edificio con relacion a la corta radiacion de los puntos de vista, por cuia causa me parecio oportuno y aun necesario no adelantar en cuerpo de columnas que hace medio en la fachada, mas que la porcion de terreno necesario al buen efecto de la decoracion, teniendo en consideracion que dho cuerpo de colunas debia tener mas altura que la del orn. y la de un proporcionado recivimiento que bastase a sostener con gracioso aspecto el coronamiento, con el fin de que los Espectadores tubiesen la comodidad de verlo todo sin fatiga de una sola mirada.

"CUADERNOS DE ESTUDIOS GALLEGOS", Tomo XLV, Fascículo 110, Santiago 1998. 
Vencida esta dificultad seguiase necesariamente disponer y ordenar la escalera al lado derecho (como debe practicarse en todo buen edificio) en la mas corta cantidad de terreno para que el sobrante resultase en beneficio de las aulas, disponiendola de tal modo que a pesar de su poca area, proporcionase el perimetro necesario a los peldaños o escalones que habian de componerla. Con efecto asi de esta manera dispuesta al lado del zaguan ó portico combinada con las demas piezas, ofrece en todos los detalles de graduacion, todo quanto puede desearse segun la capacidad del terreno, asi en decoro y regularidad, como en comodidad y economia, con la circunstancia de que en el piso del Terreno y principal franquea toda la combeniencia y desaogo que exige el uso a que es destinado este edificio.

Con relacion a todo lo dho indique la idea, en cinco apariencias o vestigios, que son, Planta del Terreno, la del Piso Pral., la Fachada, y el Corte o Seccion dada por el Zaguan, y ademas otro Corte de la Galeria, dado por la puerta que da entrada a la Iglesia, representando todo geometricamente.

La Planta del Terreno señalada con el $n^{\circ} 1$ manifiesta la disposicion de las piezas que incluye el nuebo proyecto, que son zaguan, escalera, y tres aulas de proporcionada estension.

En este pido luego que se entrá por la puerta principal se encuentra con el zaguan, desde cuya pieza se toma inmediatamente al lado derecho por el primer arco que se comunica con la escalera compuesta de tres tiros que conducen a desembarcar en el vestibulo que se comunica con la galeria alta y la havitacion del Conserge. Los que se limitan solo a entrar en las oficinas del terreno desde el predho zaguan, lo pueden hacer por los otros dos arcos segundo y tercero que conducen a la puerta que hace medio en el patio o por la que esta frente de la principal, de modo que con esta tan oportuna disposicion no solamente se logra hacer uso de toda la area de la escalera, sino la circunstancia apreciable de poder practicar con mucha felicidad por debajo de esta la otra que conduce al subterranio de un modo que apenas se hace sensible.

La Planta del quarto principal marcada con el $n^{\circ} 2$ no difiere esencialmente de la del Terreno mas que en la pieza que dice encima del zaguan, y en el menor grueso de paredes; pues quanto a las mas piezas de que consta son las mismas que las inferiores.

"CUADERNOS DE ESTUDIOS GALLEGOS", Tomo XLV, Fascículo 110, Santiago 1998. 
El $n^{o} 3$ representa la fachada principal de este Edificio decorada y adornada con la mayor sencillez y grandiosidad. Quatro colunas de orden jonico constituye el ornato exterior de esta fachada, dos de ellas pegadas, y las otras dos exentas; cuyas colunas en proporcionadas distancias alternadas con las ventanas aguantan y sostienen magestuosamente el entablamento, en el qual va colocado un tablero proyecto que coge la altura del friso y arquitrabe para colocar la inscripcion que por Real Providencia esta mandado colocar en todo edificio publico. Sobre el entablamento va colocado un gracioso recivimiento en que esta apoyado con mucha magestad el escudo Real de España que lo sostienen dos estatuas boladoras, la una representa la fama y la otra un genio, todo con alusion a la Real proteccion que los Monarcas dispensan y han dispensado siempre a tan dignos establecimientos.

El $4^{\circ} n^{o}$ manifiesta el Corte o Seccion dad por la linea A.B en que se obserba la galeria baja y alta, el zaguan con su decoracion, el primer y segundo tiro de la escalera y el vestibulo que inmediatamente se comunica con la galeria alta y la primera pieza de la habitacion del Consege.

Finalmente el $n^{\circ} 5$ representa la disposicion de las aguas del texado de la Iglesia, y la puerta que por la galeria baja se comunica con dha Iglesia; cuyos dibujos contienen todas las dimensiones y relaciones que exige la construccion de esta obra, a cuyas circunstancias se deve agregar la de escoger un profesor de conocimientos fundados en el arte de construir y mas requisitos indispensables que exige todo constructor para seguir la mente del Arquitecto todo lo qual asi executado dara pruevas relevantes del buen gusto y del acierto de los fundadores. Santiago Agosto 9 de 1798. Melchor de Prado y Mariño >> (rubricado). Cf. A. H. U.S. legajo 164, mazo 2, $n^{\circ} 17$, s. f.

Otro memorial, 7 de julio de 1799.

$<<$ Señor Retor y Señores de la Junta de Obra de la Real Unibersidad.

D. Melchor de Prado y Mariño Arquitecto y Academico de merito de la Real de Sn. Fernando, y Comisionado por S. M. en la parte artistica del Viage literario del Reyno de Portugal, con el debido respeto expone a $V$. S. que respecto sus Diseños han sido aprobados y celebrados por el Señor Rector y Señores que componen el Real Cuerpo de la Unibersidad

"CUADERNOS DE ESTUDIOS GALLEGOS", Tomo XLV, Fascículo 110, Santiago 1998. 
para que por ellos se siga constantemente la construcion de la obra que resta por hacer, y supuesto los señores de la Junta de obra al tiempo de hacerle el encargo le han asegurado que seria Director de la fabrica de la obra futura, (como a qualquiera parece regular y aun de justicia) en esta inteligencia ordenó y dispuso los Diseños nada mas que quanto fuesen oportunamente suficientes a formar en general la idea de la apariencia exterior del edificio, la del piso del terreno, y la del principal, sin atender a los otros despiezos que en obras de semejante entidad deben orientar el proyecto para hacerlo inteligible al artista mas consumado, sin hacerse cargo ni aun de pensado que la direccion de la obra habia de recaer en un sujeto que si hacer agrabio a su practica, no tiene obligacion, ni es de su instituto la direccion de obras de esta naturaleza; pues la execucion de monteas, perfiles, partes en grande, y otros trabajos relatibos al decoro del edificio, a su ermosura, comodidad, firmeza, y economia, son todos de la inspeccion del Arquitecto, y no es posible hallar estas qualidades en un oficial construtor sea quanta fuese su practica y exercicio en la materia; cuyas circunstancias deben tener presentes los Señores de obra si desean realizar felizmente y con subceso sus empresas para no conocer el daño quando es impracticable el remedio: las obras buscan los buenos Artistas; pero los buenos Artistas no buscan las obras. El exponente no se niega ni puede negarse a dirigir una producion suya, especialmente en una obra que puede acreditarle, y por lo mismo se conoce a las claras que es y fue incierto quanto se pudo haber dicho de que no queria dirigirla, respecto no ha sido llamado ni aun consultado. Ademas de que la obra no puede salir bien corregida aun siendo dirigida por sujeto de iguales disposiciones que el que formo los diseños, con que, que hara quien no esta penetrado de aquellas relaciones ocultas, de aquellas formas sencillas y grandiosas que ligan entre si y con el todo unas partes con otras, aciendo agradable lo necesario, y lo necesario agradable. Es constante y mui cierto que los edificios publicos deben ser dirigidos desde la primera piedra hasta la ultima por los suxetos de conocida idoneydad, buena prueba de esto mismo son los repetidos decretos de ntro. Soberano que prohiben la direccion de toda especie de fabricas a todos aquellos que no se han suxetado a los examenes rigurosos de las Academias de Sn. Fernando y de Sn. Carlos en el Reyno de Valencia.

Vaxo de estas consideraciones y de la obligacion que el exponente está constituido no solo por el interes que le resulta de que salga la obra

"CUADERNOS DE ESTUDIOS GALLEGOS", Tomo XLV, Fascículo 110, Santiago 1998. 
como es devido, sino por el propio de V. S. y de la patria, no puede menos de hacer presente a V. S. que es mui necesario y preciso a la perfeccion de la obra el que se nombre un Director idoneo que sea capaz de dar cuerpo con explendor y excelencia a las ideas de V. S., pues de otra suerte siempre resutaran arrepentimientos con descredito del exponente, daño de $V$. S. y perjuicio del publico. Santiago Julio 7 de 1799. Melchor de Prado y Mariño $>>$ (rubricado). Cf. A. H. U. S. Leg. 164, mazo 2, n 20 , s. f.

$\mathrm{N}^{\circ}$ II. Documentación referente a la obra escultórica.

Petición de Manuel de Prado y Mariño, 21 de julio de 1802

$<<$ Señor Rector y Junta de obra de esta Real Universidad. Señor.

Dn. Manuel de Prado y Mariño profesor del noble Arte de Escultura, con el mas atento respeto suplica a V. S. se sirvan poner a su cuidado el desempeño de la obra de Escultura, que piensan V. S. azer para el coronamiento de la fachada de esta Real Universidad de Santiago, seguro de que la desempeñara, con aquel cuidado y esmero, que exsije por nesidad: que asi lo ha echo en otras muchas que tiene echo, asi en esta ciudad, como en diberas partes de Galicia.

Es favor que espera recevir de la noctoria bondad de V. S. siempre que le consideren sujeto idoneo para su desempeño. Santiago y Julio 21 de 1802. Manuel de Prado y Mariño >> (rubricado). Cf. A. H. U. S. Sección Histórica, Universidad, leg. 164 , mazo $2^{\circ}, n^{\circ} 21$, s. f.

Postura de Manuel de Prado y Mariño, 11 de septiembre de 1802

$<<$ Sr. Retor y Junta de obra de esta Real Universidad de Sant ${ }^{o}$. Señor.

Dn. Manuel de Prado y Mariño Escultor y vecino de esta Ciudad de Santiago con el mas atento respeto expone a V. SS. como se halla encargado por el Sr. Dn. Agustin de Vales para dar a V. SS. el coste que debe tener la Escultura que se piensa hacer para el Coronamiento de esta Real Universidad, y echo cargo de esta obra, y haviendola calculado mui por menor en su cumplimiento dice, que trabajada con aquel cuidado que requiere una obra tal devera tener de coste, veinte y siete mil quatrocientos setenta reales siempre que el escultor no tenga otra cosa

"CUADERNOS DE ESTUDIOS GALLEGOS", Tomo XLV, Fascículo 110, Santiago 1998. 
que poner que canteros a su costa para trabajar y su persona asta su ultima conclusion, siendo de quenta de la Universidad arrancar la canteria, desbastarla por maior conducirla, y armar las figuras en bruto en el taller, bajo las dimensiones que diese el Escultor con arreglo a un modelo que deberá formar de su quenta. Asimismo será de quenta de dha real Universidad el poner de su quenta las alas que deben ser de cobre algun trofeo grapas, espigos de bronce, o qualquiera otra pieza de esto o otro metal que se necesitase, apunte de Herramientas estadas aparejo y todo lo mas que se necesita para su asiento y asimismo, sera de su quenta luego que las figuras esten concluhidas reconocidas, cotejadas con el modelo y aprobadas subirlas y asentarlas en sus respectibos sitios a lo que deberá asistir el escultor para que se ejecute esta operacion con el maior cuidado y esmero: y siempre que por una casualidad se esportillase o rompiese alguna parte de ellas será de quenta del escultor componerlas asta dejarlas colocadas con toda perfeccion y sin falta alguna. Para todo lo qual hara un modelo corregido lo menos de media bara cada figura el que expone y dará con el una exacta ydea a V. SS. de como debe ser la obra en grande y por donde conoceran si es o no sugeto para poder desempeñarla ademas de las diferentes obras que tiene echo en esta y en otras partes que le acredita como tambien desde luego dará fianzas abonadas para el seguro de V. SS.

Es quanto puede decir en el asumto obrando con la maior equidad en lo que suplica a V. SS. que siempre que le consideren sugeto para poder desempeñarla se sirban atenderle con dha obras pues el que suplica no desea hacer esta obra por los intereses que pueda tener solo si por la fama que puede darle, y creditos que pueda ofrecer. Santiago once de Septiembre de mil ochocientos dos. Manuel de Prado y Mariño $>>$ (rubricado). Cf. A. H. U. S. Sección Histórica, Universidad, leg. 164, mazo $2^{\circ}, n^{\circ} 21$, s. f.

\section{Informe de José Ferreiro}

$<<$ Señor Dn. Agustín de Vales. Señor.

He reconocido la obra que yntenta construir de Esculptura para el remate y frontis de la Rl. Unibersidad, dijo que debera ser de qta. de dha Unibersidad el Desmonte de las piedras necesarias en la cantera para

"CUADERNOS DE ESTUDIOS GALLEGOS", Tomo XLV, Fascículo 110, Santiago 1998. 
que los carretos sean mas moderados, y asi mismo el hacer las juntas a dhas piedras para su union, el subirlas a su asiento despues de concluydas como ygualmente todas las estadas necesarias, el apuntamiento de erramienta, y qualquier atrebuto o piesa que sea necesario ser de cobre u otro metal, y en qto. a su coste dijo que haciendose como se debe y requiere el edificio, sea por el horden que esta demostrado o por el que $V$. SS. determinen para formar los modelos necesarios para su puntual ejecucion, y no siendo qualquer mudanza considerable su coste es treinta y tres mil reales. Josef Ferreyro >> (rubricado). Cf. A. H. U. S., Sección Histórica, Universidad, legajo 164, mazo 2, nº 8, s. f.

Postura de Antonio Pernas, 15 de septiembre de 1802

$<<$ Señores Presidente y Sres. de la Real Universidad de esta ciudad. Señores

Antonio Pernas Profesor del Noble artte de esculttura, vezino de esta ciudad, con la mas profunda atencion a V. SS. hace manifiesto la de ser en su facultad suxeto habil e ynteligente segun esta dado a demostrar por sus obras como entre ellas lo han sido las Fuentes de canteria fabricadas en la Ciudad de la Coruña (cuios modelos se aprobaron por el Academico y Mro. de S. M. Dn. Manuel Alvarez) como igualmente el Panteon del Yllmo. Sr. Malbar en su Capilla del Salzedo: el que le consta a dn. Joseph Machado que lo es Mro. de dha Universidad; Y mediante tiene entendido el que representa la de haverse llamado para dha obra a dn. Joseph Ferreiro como capaz en su arte? Savedor de esto entro Dn. Manuel de Prado asimesmo profesor en el expecificado arte, por medio de un memorial expresando en el la revaxa al dho Ferreiro en la obra; cuio dn. Manuel no tiene dado a demostrar obra publica de canteria, como lo tiene echo ver el exponente y asi y entendiendolo.

Suplica a V. SS. se sirvan admitirle la postura de veinticuatro mil reales vellon gracia que espera merecer de la grandeza de V. SS. Santiago y Septiembre 15 de 1802. Antonio Pernas >> (rubricado). Cf. Idem, Representaciones de los Profesores de Escultura y Pintura, sobre las obras de esta Real Universidad.

"CUADERNOS DE ESTUDIOS GALLEGOS", Tomo XLV, Fascículo 110, Santiago 1998. 
Postura de Bartolome Fernández, 17 de septiembre de 1802

$<<$ Señor.

Bartholome Fernandez Maestro Estatuario vezino de esta Ciudad: noticioso de que la Real Universidad, ba a poner a posturas la obra de Escultura para su fachada y que para ella admite los postores que se presenten, y se contemplen capaces de desempeñarla, desde luego como uno de los tales profesores se declara postor bajo las condiciones siguientes.

$1^{a}$ No ha de entenderse por cuenta suia el arranque de piedra: el desmontarla por maior: hacer las juntas para su union ni la conducion, $e$ ygualmente el armarlas en el taller que deberá franquearsele al efecto.

$2^{a}$ Tampoco será de su cuenta el apunte de Erramientas alas para los Niños si se ofrecen, que deverán ser de cobre o metal algun otro espigo geroglifico o signo propio de la figura que deverá ser de lo mismo.

$3^{a} Y$ ultima.... Ygualmente no serán de su cuenta las Estadas, Asientos, y todo lo mas necesario para la respectiva colocacion de las figuras en su oportuno lugar y solo a dicha colocacion asistirá el que subscrive: todo lo demas no exceptuado aqui asi para abrir el Escudo de Armas como las Estatuas queda a cargo del suplicante; bajo estas condiciones hace su postura en la cantidad de veinte y cinco mil reales firma Santiago Septiembre 17 de 1802. Bartolome Fernandez >> (rubricado). Cf. A. H. U. S. Sección Histórica, Universidad, leg. 164, mazo $2^{\circ}$, n 21, s. f.

Contratación de la obra con José Ferreiro, 31 de enero de 1803

$<<$ Escritura de contrata que otorgaron los Dres. Dn. Agustin Vales Vaamonde y Dn. Vicente de Neira a fabor de Dn. Jph Ferreiro.

En la Ciudad de Santiago a treinta y un dias de el mes de Henero año de mil ochocientos, y tres, ante mi Secretario y testigos parecieron presentes los Doctores Dn. Agustin Vales Vaamonde, Cathedratico de Visperas de Leies, y Dn. Vizente Josef de Neyra Cathedratico de ynstituciones Civiles, e yndibiduos de la Junta de Obra, y digeron que por los sres de ella se les dio facultad para que tratasen y ajustasen con el Escultor que contemplasen mas a proposito la construccion de Estatuas, Grupos, y Escudo de Armas Reales que deben colocarse en la fachada de el edificio

"CUADERNOS DE ESTUdIOS GALLEGOS", Tomo XLV, Fascículo 110, Santiago 1998. 
de dha Real Unibersidad. A consequencia de que despues de varios ynformes que han tomado llamaron a Dn. Josef Ferreiro Escultor, vecino de esta referida Ciudad, a él que ynstruieron de las Estatuas que él Claustro tenia acordado poner en el Frontis de su edificio. Enseguida él mismo formó el Plano que los otorgantes presentaron a los Señores de la mencionada Junta de obra, que le aprobó, y han firmado los dos que otorgan con él presente Secretario, y entregaron a dicho Ferreiro, con él que ajustarón la apertura de el Escudo de Armas Reales y mas obra que contiene él diseño, en la cantidad de treinta mil Reales vellón, y hallandose presente él mencionado Dn. Josef Ferriro se obliga con su persona y vienes presentes y futuros, a egecutar la óbra conforme al diseño vajo las condiciones siguientes = Que ha de ser de quenta de la Real Unibersidad, el desbaste de las piedras necesarias para las Figuras en la cantera, su conduccion, y hazer las Juntas para su union, colocarlas unas sobre otras a fin de que él, y sus oficiales puedan travajarlas. E ygualmente despues de concluidas las Figuras en él obrador apearlas, y colocarlas en su lugar, para todo lo que la Unibersidad le há de dár las Estadas necesarias, costear el apunte de erramientas para toda la construccion de dha obra, y qualquiera pieza que deba ser de metal, yá para atributo, o grapa, y al principio de la obra entregarle diez mil reales, a la metad de ella otra tanta cantidad y a su conclusion de reconocida, y aprobada los restantes diez mil reales y con estas condiciones se obliga asistir en la cantera ál desbaste de todas las piedras necesarias para la mencionada obra, y asi mismo a todas las operaciones hasta su conclusion, y egecutarla segun arte con la perfeccion posible, y arreglo al Plano que él hizo, y existe en su poder firmado de los dos Sres. otorgantes y de el presente Secretario; y cumpliendo con lo que solicita Ferreiro le entregarón en este mismo acto la cantidad de diez mil reales en monedas de plata que contó, y llevó a su poder de que yo Secretario doy fee; de cuida cantidad les otorga recivo y carta de pago en forma, y ademas de ello se obligan que a costa de las Rentas, y efectos de la Unibersidad le pagarán los restantes veinte mil reales en los plazos señalados, y que de quenta de la misma Universidad se costeará él desbaste de las piedras, su conduccion, el apunte de erramientas para toda la obra, le dará las Estadas y qualquiera pieza que deba ser de metal. Y todos tres otorgantes se obligan a que estarán y pasarán por lo capitulado en esta Escritura, y lo hará el Claustro, y se sujetan a las Justicias de su fuero 
y Jurisdicion para que se lo hagan cumplir, y no lo haciendo consienten ser apremiados a ello y pagar todos los daños costas y perjuicios que de su omision o falta se ocasionaren. En testimonio del qual asi lo digeron y otorgaron siendo testigos Dn. Miguel Francisco de Prado, Dn. Pedro Miguel Caravelos, residentes en esta Ciudad, y Fernando de Andrade vezino de la misma, de todo lo qual y conocimiento de los otorgantes yo Secretario doy fee $=D r$. Dn. Agustin Vales Vaamonde. Dr. Dn. Vizente Josef de Neira. Josef Ferreyro. Ante mi Luis Coton>>. Cf. A. H. U. S. Protocolos. Luis Cotón, y Bermúdez, año 1803, reg. 7277, fols. $1-1 \mathrm{v}$.

\section{$\mathrm{N}^{\circ}$ III. Documentación relativos al blanqueo de la obra escultórica} Contrato con Plácido Fernández Erosa, 24 de julio de 1804

$<<$ Escritura de contrata y ajuste echa entre Dn. Vizente de Neira y dn. Placido Fernandez.

En la Real Universidad de la Ciudad de Santiago a beinte y quatro dias de el mes de Julio año de mil ochocientos quatro, ante mi escribano y Secretario de dha Unibersidad, y testigos parecio presente el Dr. Dn. Viente Josef de Neira, en virtud de comision dada por la Junta de Obra de la misma dha Real Unibersidad ha hajustado con Dn. Placido Fernandez, maestro Pintor la Pintura de las Estatuas, Escudo Real, Leones y Tablero que decoran el frontespicio de la obra bajo las condiciones siguientes.

Primera Se limpiaran todas las referidas piezas del polvo que puedan tener, y escanarán de la cal las juntas de las piedras, las que se embetumaran con betun de oleo, igualandola en la superficie de modo que en ningun tiempo se descubran dhas guntas.

Segunda Se dara a las citadas piezas una mano de aceite de linaza caliente mezclando con litargirio u otro igual desecante, para cerrar los poros de la piedra, y conseguir que el color se fixe en ella con mas permanencia.

Tercera. De echa esta preparacion se les daran cuatro manos a brocha de albaialde bien pastoso molido con aceite de linaza.

Quarta. En seguida se daran las manos que sean necesarias de albaialde fino hecho masa preparado con aceite craso de nuezes, cuias

"CUADERNOS DE ESTUDIOS GALLEGOS", Tomo XLV, Fascículo 110, Santiago 1998. 
manos habran de ser a pulimento de modo que se consiga tersura e igualdad en la superficie, como igualmente blancura en todas las partes que componen la decoracion del frontispicio, es a saber estatua de Minerba, grupos, escudo Real, Leones, y tablero donde se ha de colocar la inscripcion.

Quinta Se doraran los trofeos de las estatuas con paneles mas incorporados que los ordinarios, é igualmente las letras de la inscripcion; las quales se habran de gravar en la piedra por quenta de la Unibersidad para que su dorado sea mas permanente, de quenta de la qual sera tambien qualquiera estada que haga falta.

Sesta. Que quando se quiera principiar a dar la primera mano haya el Dn. Placido de abisar al sugeto que la Junta le señale para que este pase a rreconocer si las piezas estan en disposicion de recivirla, y si el color que se va a emplear tiene la conducente preparacion; lo mismo se ha de verificar en la segunda mano, tercera, y todas las mas hasta la ultima.

Septima. Que concluida toda la obra segun el metodo expresado; y precedido su reconocimiento, y bisto bueno ha de tener cumplido la Real Unibersidad con entregar al Dn. Placido doce mil reales vellon, en cuia cantidad se ha ajustado con el citado Dr. Dn. Vicente Josef de Neira, bajo expresa capitulacion de que no repitira partida alguna de esta cantidad hasta que como va dicho; sea del todo concluida la obra, y realiza su aprovacion en todas las quales condiciones combino el citado Dn. Placido, y a su cumplimiento se obliga, y allana en forma, como tambien a que inmediatamente dara principio a la motibada obra, y la dara concluida en todo el veradno de este presente año, sin dar lugar a que se interrumpa su prosecucion con las aguas del invierno y unas y otras partes se sugetan compoder bastante a las Justicias de S. M. su fuero y Jurisdicion, y domicilio para que asi se lo hagan cumplir guardar y haber por firme como si lo aqui contenido fuera sentencia difinitiba dada por Juez competente... >> . Cf. A. H. U. S. Protocolos. Luis Cotón, y Bermúdez, año 1804, reg. 7278, fols. 6-6v.

Informe de Plácido Fernández de Arosa, 9 de octubre de 1804

$<<$ Sr. Rector y Señores Directores y Yndividuos de la Junta de obra de esta Real Univesidad. Señores.

"CUADERNOS DE ESTUDIOS GALLEGOS", Tomo XLV, Fascículo 110, Santiago 1998. 
Dn. Placido Fernandez, maestro Pintor, vecino de esta Ciudad con el respecto que deve, hace presente a V.SS. haver tomado a su cuidado la pintura de las Estatuas y mas escultura que decora la principal fachada del edificio la que ajustó y se remató a su fabor baxo las capitulaciones que por menor se comprenden en la escritura que para seguridad de esta Real Universidad, otorgo a su fabor y debe exsistir en la Secretaria de ella siendo condicion que dicha obra la ha de concluir a satisfaccion de la Junta y en efecto haviendo se le construido la correspondiente estada, procedio al desenpeño de su obligacion y teniendola concluida a su satisfacion se lo participó al Señor decano presidente de la Junta el Docttor Dn. Agustin de Vales, quien tubo a bien proceder a su reconocimiento acompañado del pintor Mariño, perito que buscó como de su satisfacion, quien haviendola reconocido, como hallase cierta diferencia de color entre el escudo y las Estatuas y que en estas en razon de su maior elevacion el fuerte aire que hizo quando el exponente le dio la ultima mano y el haverse demolido la estada se les havia internado alguna porcion de polbo, decidio que para la maior perfeccion blancura y ultimacion de la obra devia el exponente darle dos manos mas de albaialde lo mismo que dicho Señor decano intimó al exponente para que lo executase quien no se resistió a ello, antes todo lo contrario, pues siendo como es su animo dar gusto a esta Real Universidad y otros qualesquiera que ponen obras a su cuidado contesto lo executaria inmediatamente sin que por ello huviese el menor motibo de quexa, de que quedó satisfecho dho señor decano manifestando su contento, y al efecto en la tarde del mismo dia paso oficio al Doctor Dn. Benito Carrera para que dispusiera la formacion de la correspondiente estada; y cuando el exponente, esperaba que esta se construiese con la devida prontitud para ultimar dhas estatuas segun lo prevenido por dho perito y Señor decano se halla sorprendido en el dia de aier con una esquela sin fecha que dho señor tubo a vien enviarle en la que manda no pase a travajar en las estatuas ni darle mano alguna hasta que diese parte a esta Junta y al claustro para que resuelban lo que tengan por conveniente añadiendo que en defecto se ocurrira a la Justicia contra el exponente.

La justificacion de la Junta conoce mui vien las razones que asisten al exponente para quexarse de un echo tan irregular; sabe mui vien la obligacion que ha contraido en virtud de la qual, y aun sin ella por solo su honor ha de perfeccionar y dejar concluida su obra a satisfacion de la 
junta del claustro y aun del publico. Tamvien conoce que siendo la composicion de la pintura de esta obra de azeite y albaialde es un inposible que al instante quede con toda la blancura que se desea a causa de los mismos azeites lo que se consiguirá depurandose estos con el tiempo como se ve en otras obras de esta clase; y se conseguiría al instante si la composicion fuese de cal de Lugo y agua de cola.

Entre las capitulaciones echas para esta obra es una que la junta por su quenta havia de poner un sugeto que presenciase la pintura; quando el exponente quiso comenzarla se lo notificó por si mismo a dho señor decano para que enviase el tal sugeto, lo que no hizo contentandose con haver tomado la molestia de subir por si mismo a reconocerla en su principio concluido el exponente se ha visto la obra por perito de la satisfacion de dho señor, expuso dever aun darsele a las figuras otras dos manos de albaialde, el exponente estaba y está pronto a executarlo, luego no se alcanza el motibo por que se le mande suspender; ya la verdad no puede ser otro mal que a influxo del mismo perito que resentido de no haver echo la obra se enpeña en incomodar la junta, y comprometer el honor de este respectable cuerpo y la estimacion del exponente, quien se dará por satisfecho con que su obra sea vista por los peritos de maior inteligencia que sean de la dignacion de V. SS.

El exponente no quiso recivir dinero alguno para la construccion de su obra costeandola de su bolsillo por lo qual nada deve a la Universidad, quien le pagará lo ajustado concluida segun las capitulaciones de las que se excedio el exponente dando mas manos de las que correspondia solo por contentar a la Unibersidad, por lo qual extraña infinito se le amenace con la justicia que solo se hace quando se trata de suxetos que se desentienden de cumplir con su obligacion y se hacen acreedores a ser castigados pero todo lo contrario se ve en la autualidad.

Por todo lo qual suplica a la Junta se sirba tomar las providencias de su agrado mandando se havilite la estada para dar las dichas dos manos a las estatuas que lo hará aunque sea a presencia de qualquier sugeto de su satisfacion y de echo se le de libre el inporte de la obra segun estaba escriturado y de lo contrario, que no expera de la justificacion de V. SS., hablando como corresponde protesta hacer sus recursos al claustro, y mas a donde convenga, para lo que pide que el Secretario le de testimonio de esta representacion y de lo que V. SS. tenga a vien acordar en el

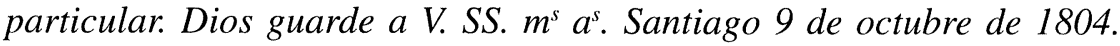

"CUADERNOS DE ESTUDIOS GALLEGOS", Tomo XLV, Fascículo 110, Santiago 1998. 
Placido Fernandez Arosa >> (rubricado). Cf. A. H. U. S. Sección Histórica, Universidad, leg. 164 , mazo $2^{\circ}, n^{\circ} 21$, s. f.

Informe de Manuel de Porto y Mondragón, 25 de octubre de 1804

$<<$ Yo Manuel de Porto, y Mondragon Profesor en el Arte de Pintura y dorado, he sido llamado por el Señor Dn. Agustin de Vales para el reconocimiento de la pintura de blanco, que dn. Placido Fernandez tomó a su cargo dar á las Estatuas, y Escudo de las Armas Reales, que están sobre la Portada principal de la Real Universidad, devo decir, y digo, que haviendo reconocido todo muy por menor hallé, que el blanco dado en dhas Estatuas está mal operado; en unas partes cargado, y en otras conociendose las primeras manos de las imprimaciones, y descubriendose la aspereza de la piedra; prueba de que el sugeto que lo dio no tenia practica ni instrucion, ni era facultativo; pero la dha pintura (sin embargo de su mal operacion) está segura, y sin riesgo de que pueda falsear; pues la calé con fierros, la froté lo bastante, y nada descubrí en contrario.

Asi mismo reconocí el material que tiene preparado en unas cazuelas, que es de albayalde fino, y bien molido: de qual deve el dho Dn. Placido darle o mandarle dar por facultativo práctico, y experimentado dos manos, la primera pastosa, (particularmente en las partes donde estan mal cubiertas) y la segunda generalmente cn buen varniz, y a pulimento: $y$ caso no alcancen, darle tres: a fin de que queden bien cubiertas, terso el color, y que parezcan las dhas Estatuas de marmol.

Quanto al Escudo de las Armas Reales está decentemente dado, terso, y con bastante blancura, que puede pasar muy bien.

Es lo que puedo decir sobre éste particular segun mi corto alcance y lo firmo: Santiago 25 de octubre de 1804. Manuel de Porto y Mondragon >> (rubricado). Cf. A. H. U. S. Sección Histórica, Universidad, Leg. 164 , mazo $2^{\circ}, n^{\circ} 21$, s. f.

"CUADERNOS DE ESTUDIOS GALLEGOS", Tomo XLV, Fascículo 110, Santiago 1998. 
Informe de Plácido Fernandez de Arosa, 26 de noviembre de 1804

$<<$ Sr. Rector de la Real Unibersidad de Santiago. Señor.

Dn. Placido Fernandez profesor de pintura de esta Ciudad,.. expone a V. S. haver tomado a su cargo la pintura de las estatuas y escudo que decoran la fachada de la Real Universidad, ajustada en doze mill reales siendo de su cargo costear todos los materiales necesarios, capitulando barias condiciones terminantes a la perpetuidad, solidez y blancura y que concluiendo dicha obra se le havian de entregar dichos doce mill reales, como todo resulta por menor de escritura otrogada que debe exsistir en la Secretaria. Pasó por si mismo y por medio de oficiales a cumplir con su obligacion, y teniendo concluido, quando V. S. estaba ausente dio parte a los señores de la junta de obra para que procediesen a su reconocimiento que asi lo hicieron algunos por si mismos y mandaron deshacer las estadas en cuia operacion como el aire obligase a alguna porcion de polbo a pegarse en algunas partes de dhas figuras llamo el Señor Bales por si solo un perito, quien las reconoció y expuso que el escudo estaba vien pero que las estatuas necesitaban mas blanco para su maior perfeccion, el exponente no reuso executarlo, y le dio el que parecio preciso a contento de dho señor, quien de acuerdo con la junta nombró otro perito y reconociendo las figuras dijo necesitaba cierta igualdad, en cuio estado el Señor Bales intimo por si mismo al exponente no travajase en las estatuas amenazandole con la justicia en cuia virtud suspendio hasta que en otra junta acordaron nombrar otro perito que haviendo echo nuebo reconocimiento dijo lo mismo que el anterior y en interin el exponente estubo detenido sin poder rematar su obra hasta que el mismo Señor Bales le mandó trabajar y acompañado de los mejores oficiales hizo quanto considero necesario para perfeccionar tal pintura, dio parte, haviendo concluido al dho Señor Bales nombro nuebo perito quien se acompaño de otro facultativo reconocio la obra y expuso a dicho señor se hallaba perfecta en todas sus partes sin necesitar de cosa alguna, y quando en este estado esperaba el exponente se le librase su dinero no sabe porque razon se le detiene, y asi mismo ignora los motivos por que el Señor Bales se enpeña en incomodarle y tratarle injuriosamente, pues se precia de haver desempeñado su comision como devia sufriendo tantas vistas que no heran necesarias para una obra de esta naturaleza. En el dia es indispensable mandar deshacer las estadas pues el agua que escurre de 
las tablas pueden manchar las figuras o derrotar alguna parte de ellas desquiciandose alguna tabla por la fuerza del temporal por cuias resultas no responde.

A V. S. pribatibamente corresponde el informarse de este asumpto y desidirlo como Rector de la Universidad, y a V. S. suplica el exponente que teniendo en consideracion que de su bolsillo costeo lo preciso para los materiales y jornales que atraso su casa, perdio otras barias obras, de mucho interes se le ha ultrajado su honor y ha sufrido lo que no devia ni quiere escribir en atencion a que solo pide lo suio con arreglo al contrato celebrado, que por su parte tiene cumplido se digne por un efecto de su bondad obrando con aquella justificacion que le es nata disponer se le libre lo que se le deve sin dar lugar a mas perjuicios como asi lo espera de la rectitud de V. S. Santiago 26 de noviembre de 1804. Placido Fernandez>> (rubricado). Cf. A. H. U. S. Sección Histórica, Universidad, leg. 164 , mazo $2^{\circ}, n^{\circ} 21$, s. f.

Escritura de obligación de Plácido Fernández de Arosa, 12 de junio de 1805.

$<<$ Obligacion hecha por Dn. Placido Fernandez Pintor a favor de la Real Universidad de Santiago.

Dentro de la Real Universidad de la Ciudad de Santiago a doce dias del mes de Junio año de mil ochocientos cinco, ante mi escribano Secretario de dha Real Unibersidad y testigos parecio presente Dn. Placido Fernandez Pintor, vecino de esta Ciudad, e dijo que mediante de la contrata que tiene echo con la referida Unibersidad en Veinte y quatro de Junio del año proximo pasado en que se obligo ademas de Pintar las Estatuas y dorar los trofeos el hacerlo de la inscricion que ha de ponerse en el frontis del edificio lo que no ejecuto por no hallarse abierta desde luego por el tenor de la presente se obliga con su persona y vienes presentes y futuros de que en qualquiera tiempo que la Unibersidad tenga por conbeniente el dorarla el hacerlo pro si o persona en su nombre con aquella perfeccion que corresponde sin que por razon de ello pueda repetir ni reclamar cosa alguna mas que los doce mil reales en que fue ajustado, segun por menor resulta de la dha contrata en la que asimismo se ratifica sin dar lugar a otro procedimiento y para que asi se lo hagan

"CUADERNOS DE ESTUDIOS GALLEGOS", Tomo XLV, Fascículo 110, Santiago 1998. 
cumplir se sujeta a las Justicias de S. M. su fuero y Jurisdicon para que asi se lo hagan cumplir y guardar y haber por firme como si lo contenido fuera sentencia definitiva dada por Juez competente pasada en autoridad de cosa Juzgada por el consentida y no apelada cerca de que renuncio todas las leyes fueros y derechos de su fabor con la General que las prohibe en forma asi lo dijo otorgó y firmó siendo a todo ello presentes por testigos el Dr. Dn. Domingo Caamiña, Dn. Josef Perez Machado, y Dn. Vicente Gonzalez Valera todos vecinos de dha Ciudad, y de todo ello y conocimiento del otorgante io Escribano Secretario doy fee. Placido Fernandez. Ante mi Luis Coton>>. Cf. A. H. U. S. Protocolos. Luis Cotón, y Bermúdez, año 1805, reg. 7279, fols. 6-6v.

"CUADERNOS DE ESTUDIOS GALLEGOS", Tomo XLV, Fascículo 110, Santiago 1998. 